\title{
STIFFNESS AND DAMPING PROPERTIES OF CELLULAR SHEAR WALLS WITH VISCOELASTIC FILLERS
}

\author{
PANAGIOTA SYRIMI ${ }^{1}$, SPYRIDOULA M. PAPATHANASIOU ${ }^{2}$ AND PANOS $^{2}$ \\ TSOPELAS ${ }^{3}$
}

\begin{abstract}
${ }^{1,2,3}$ Laboratory of Testing and Materials, Department of Mechanics, School of Applied Mathematical and Physical Sciences, National Technical University of Athens, 5, Heroes of Polytechniou Avenue, Theocharis Building, Zografou Campus, 15773, Athens, GREECE, syrimip@mail.ntua.gr, spapath@central.ntua.gr, tsopelas@central.ntua.gr
\end{abstract}

Key words: Cellular Materials, Viscoelastic fillers, Damping behaviour, Shear walls.

\begin{abstract}
Aiming to enhance the stiffness and damping properties of cellular materials, the idea of inserting viscoelastic fillers into the gaps of cells is developed. A representative volume element of typical hexagonal honeycomb cells with and without inclusions is examined under dynamic shear loading, in order to define the mechanical properties of the proposed composite material. Within each cell the viscoelastic material is either through viscoelastic shell elements or through viscoelastic bars attached to the hexagonal cell apexes. The calibrated viscoelastic bar RVE model is, by extent, implemented to a shear wall, tested under dynamic shear loading, to verify the efficiency of the viscoelastic inclusions. Finally, different viscoelastic filler patterns are explored to study the proposed system's performance.
\end{abstract}

\section{INTRODUCTION}

Shear walls are structural components frequently encountered as parts of bridge columns or structural frames [1]. In the scope of creating lightweight and efficient structures, adjustable to various geometric configurations, the idea of steel plate shear wall systems has been introduced [2-8]. However, the main disadvantage of these steel plate systems is that they exhibit out-of-plane buckling [6], creating areas of unused material. In view of removing these material areas that do not participate in the overall performance of the shear wall system, the idea of steel plate shear wall systems with perforations has been suggested [8-12].

Maximizing the number of perforations, holes or gaps of a shear wall panel, researchers resulted in the construction of shear wall structural components made out of cellular materials [13-14]. Due to their low-density format, their light weight and their good thermal behavior, cellular materials are commonly used to enhance structural stiffness and strength. The main advantage of cellular materials for shear wall systems is that out-of-plane buckling is avoided, since cellular shear walls have a significant out-of-plane depth compared to the steel plate shear wall systems.

The idea of exploiting the gaps of cellular architectures by placing infills with damping properties to enhance the overall structural dynamic response has been explored by various researchers [15-20]. However, this concept has not been transferred yet from a theoretical 
point of view to a practical design and/or analysis of a structural component or a whole structure. In the majority of the aforementioned research cases, viscoelastic materials are selected as fillers. Viscoelastic materials are commonly used in vibration absorption devices for the mitigation of the dynamic response of structures (usually high-rise buildings and bridges) under wind or earthquake loading [21-26].

In this study, the introduction of viscoelastic fillers inside the honeycomb cells of a cellular shear wall panel is proposed. First, the contribution of the viscoelastic fillers to the overall dynamic performance of the composite honeycomb-viscoelastic material is examined, through numerical analysis of Representative Volume Element (RVE) models under dynamic loading. A simplified RVE model, under the name Effective RVE-filled model, is introduced, simulating the viscoelastic fillers through bars of effective width attached to the hexagonal cell apexes, in order to simplify complex numerical analysis. The aforementioned Effective RVE-filled model is then implemented to the structural component analysis, where a fullsized shear wall system is tested under a harmonic excitation. Different patterns of arranging the viscoelastic inclusions within the shear wall panel are explored. Comparative results between the unfilled and the filled cellular shear wall systems are obtained to prove the validity and efficiency of the proposed concept.

\section{METHODOLOGY}

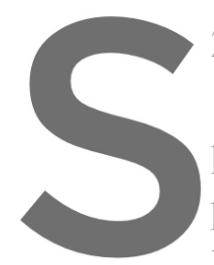

\subsection{Materials}

For the dynamic

honeycomb matrix o:

properties given in

frequently used in
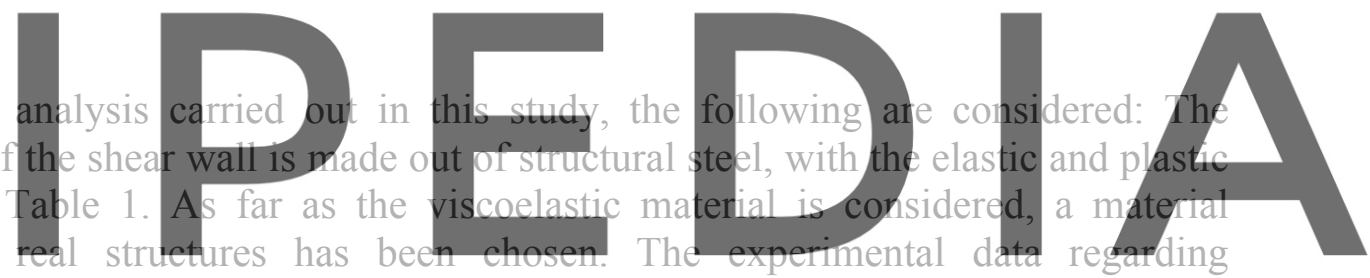

frequency, shear storage and shear loss moduli, as given in Table 2, are obtained from the

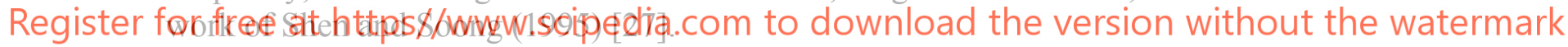

Table 1: Elastic and plastic properties of structural steel

\begin{tabular}{cccccc}
\hline $\begin{array}{c}\text { Young's modulus, } \\
\text { E (GPa) }\end{array}$ & $\begin{array}{c}\text { Poisson's } \\
\text { ratio, } \mathrm{v}\end{array}$ & $\begin{array}{c}\text { Yield stress, } \\
\sigma \mathrm{y}(\mathrm{MPa})\end{array}$ & $\begin{array}{c}\text { Yield strain, } \\
\varepsilon \mathrm{y}(\%)\end{array}$ & $\begin{array}{c}\text { Ultimate stress, } \\
\sigma \mathrm{u}(\mathrm{MPa})\end{array}$ & $\begin{array}{c}\text { Ultimate } \\
\text { strain, } \varepsilon \mathrm{cu}(\%)\end{array}$ \\
\hline 200 & 0.30 & 275 & 0.1375 & 414 & 25 \\
\hline
\end{tabular}

Table 2: Frequency-dependent properties of viscoelastic material at a temperature of $21^{\circ} \mathrm{C}$ (Shen and Soong, 1995) [27].

\begin{tabular}{ccc}
\hline Frequency, $\mathrm{f}(\mathrm{Hz})$ & Shear storage modulus, $\mathrm{G}^{\prime}(\mathrm{MPa})$ & Shear loss modulus, $\mathrm{G}^{\prime \prime}(\mathrm{MPa})$ \\
\hline 1 & 1.372 & 1.786 \\
\hline 1.5 & 1.827 & 2.248 \\
\hline 2 & 2.069 & 2.724 \\
\hline 2.5 & 2.517 & 3.192 \\
\hline 3 & 2.661 & 3.358 \\
\hline
\end{tabular}




\subsection{Dynamic behavior of cellular solid representative volume element (RVE) with viscoelastic filler}

In order to define the material behavior of the combined steel honeycombs with viscoelastic fillers, three representative volume elements (RVEs) are considered, each one consisting of seven full honeycomb cells. The first RVE model, under the name RVEHoneycomb, (Figure 1a) represents the plain steel honeycomb matrix of a cellular wall without any infills. In the dynamic computational analysis that is carried out for this model, the steel edges of the honeycomb cells are simulated with beam elements. The second RVE model (Figure 1b), from now on referred to as the RVE-filled model, has the same steel honeycomb matrix as the previous model but this time each one of the honeycomb cells is filled with the viscoelastic material. For the computational analysis of this second model, the viscoelastic material is simulated through shell elements. The comparative analysis of these two models is performed in order to prove the viability of the proposed concept and study the modification of the dynamic and stiffness properties of the RVE due to the addition of the viscoelastic material. However, since the scope of this paper is to apply the proposed concept to a full-scale shear wall system, the computational cost of simulating the viscoelastic infills through shell elements would be rather large.

Aiming to simplify the computational effort needed for more complex analysis, the Effective RVE-filled model is introduced, as shown in Figure 1c. In this model the shell surface of the viscoelastic material within each honeycomb cell is substituted with three

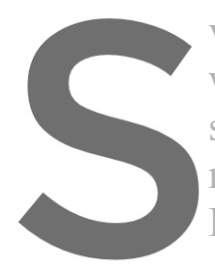
viscoelastic bars, attach whole area of the cell. simulated through bean manageable model. RVE-filled model with

Since, the RVE configurations represent ant
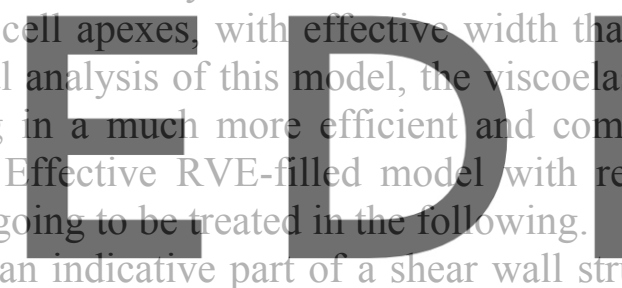

one of the three aforementioned models is subjected to a harmonic excitation simulating pure

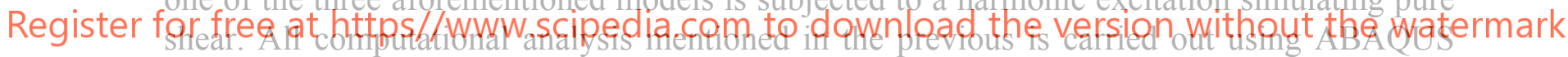
software [28].

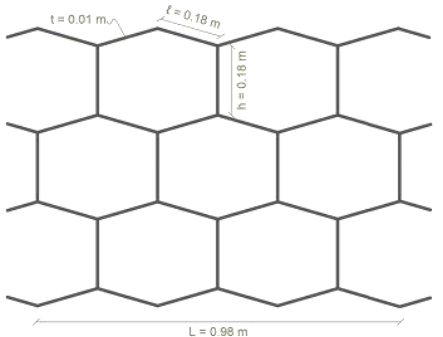

(a)

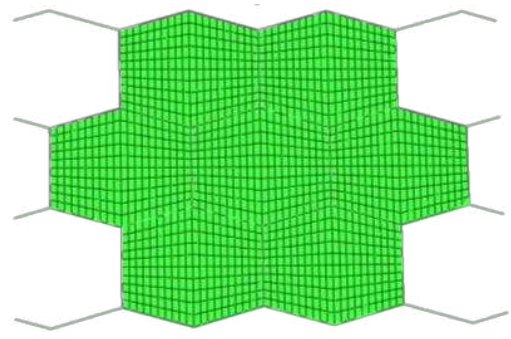

(b)

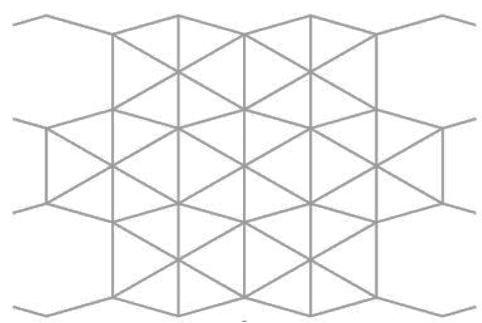

(c)

Figure 1: Representative Volume Element (RVE) models: (a) RVE-Honeycomb model, (b) RVE-filled model and (c) Effective RVE-filled model

In Figure 2a, the dynamic response of the unfilled RVE-Honeycomb model under a harmonic excitation of frequency equal to $1 \mathrm{~Hz}$ is presented. As expected, due to the bilinear behavior of steel, the RVE-Honeycomb results provide a hysteretic stress-strain curve. In 
Figure $2 b$, the dynamic response of the RVE-filled model under the same harmonic excitation of frequency equal to $1 \mathrm{~Hz}$ is given for three different values of the out-of-plane depth of the viscoelastic infills. It becomes clear that as the thickness of the viscoelastic fill increases both the stiffness and the damping capacity of the RVE increase. It is noted that due to the out-ofplane depth of the cellular shear wall the undesirable out-of-plane buckling that steel plate shear wall systems exhibit is avoided.

At this point, it should be mentioned that in order to study the damping behavior and properties of all RVE models, the values of stress at zero strain are of interest since they represent the strain-rate dependent part of the viscoelastic behavior.

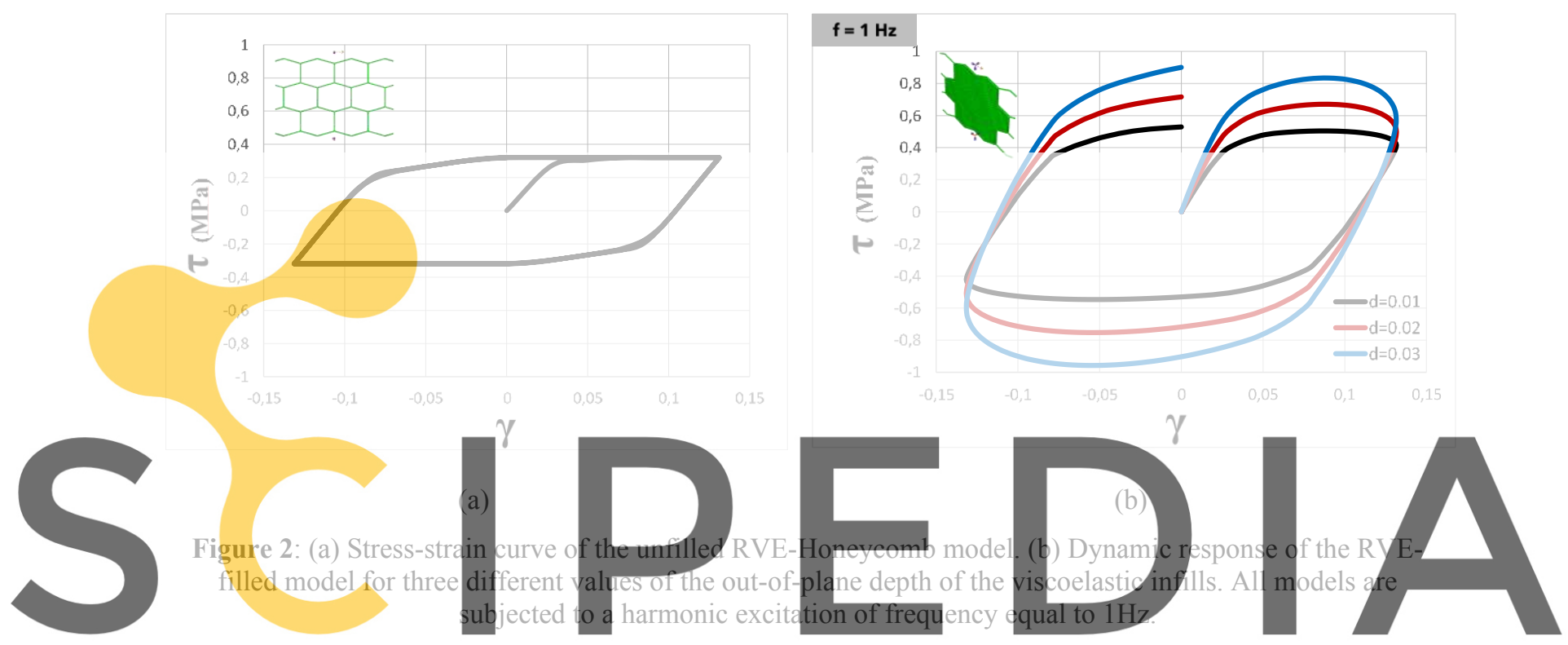

Register for free at https//www.scipedia.com to download the version without the watermark

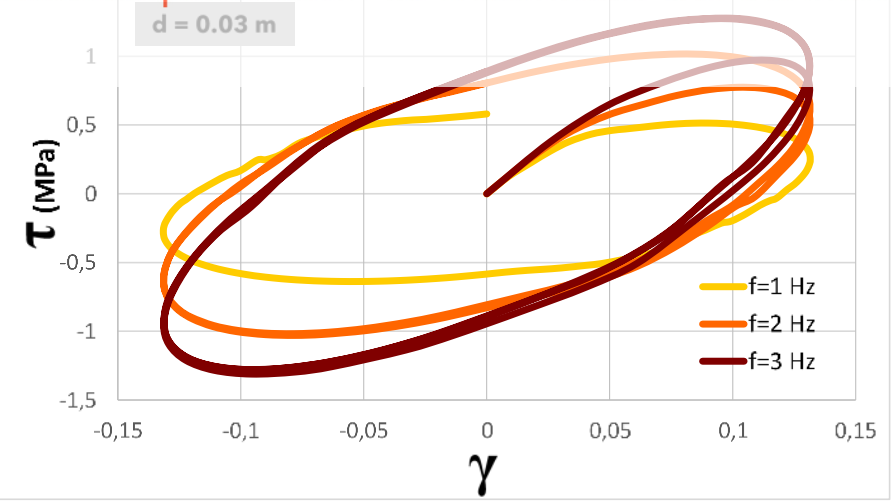

Figure 3: Behavior of the viscoelastic filler.

In view of examining the behavior of the viscoelastic fill and define its contribution to the overall performance of the RVE, the stress-strain curves, for an out-of-plane depth of $3 \mathrm{~cm}$ and for three different harmonic excitation frequencies of $1 \mathrm{~Hz}, 2 \mathrm{~Hz}$ and $3 \mathrm{~Hz}$, are shown in Figure 3. These results are obtained after subtracting the dynamic response of the RVE-Honeycomb 
model, which represent the plain steel matrix contribution, from the overall response of the RVE-filled model.

\subsection{Calibration of the Effective RVE-filled model}

As it was mentioned previously, the Effective RVE-filled model is implemented, to simplify complex computations. It is, also, reminded that in this model the shell surface of the viscoelastic material within each honeycomb cell is substituted with three bars of the same viscoelastic material attached to the hexagonal cell apexes. These are simulated through beam elements for the Abaqus dynamic analysis. In order to obtain accurate results using the simplified model, a calibration between the Effective RVE-filled model (Figure 2c) and the RVE-filled model (Figure 2b) is required.

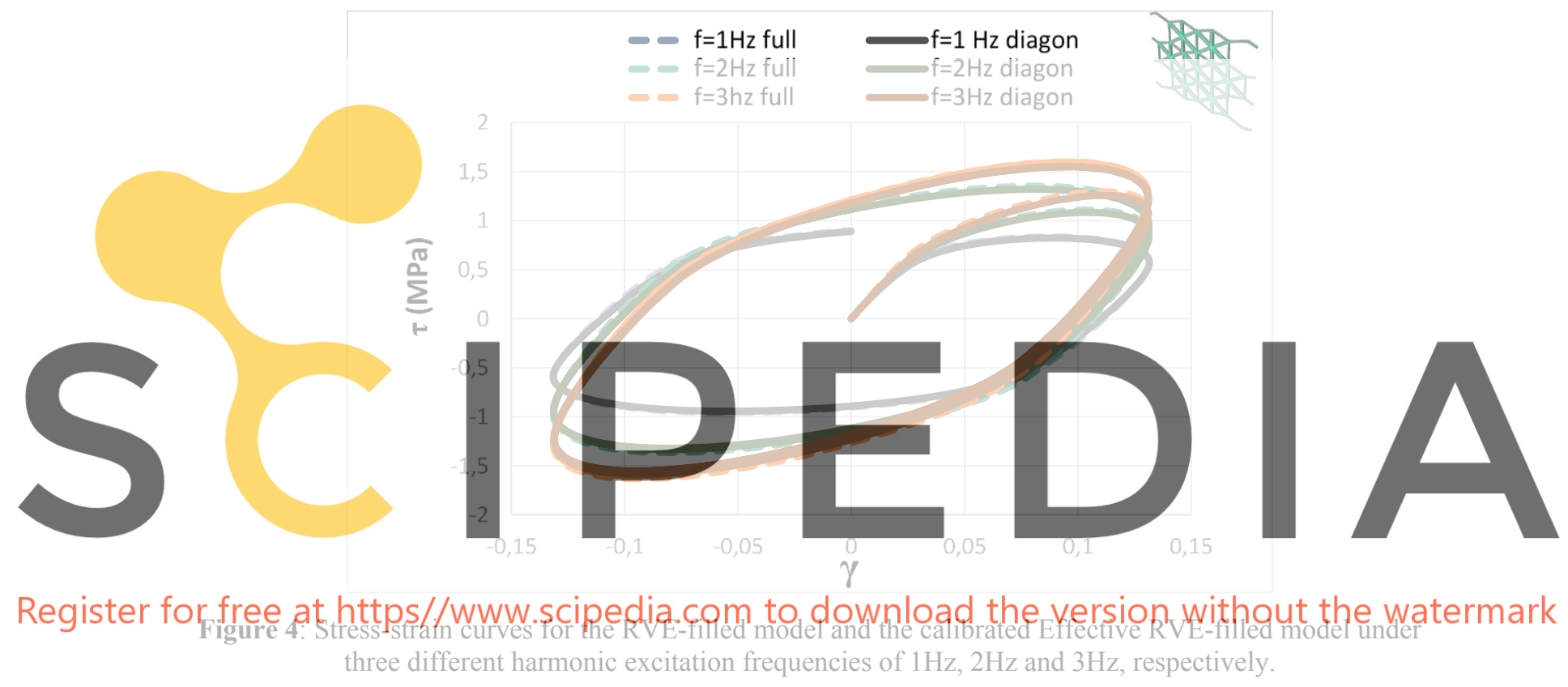

For an RVE-filled model with shell elements of out-of-plane depth equal to $3 \mathrm{~cm}$, representing the viscoelastic fillers, the equivalent three viscoelastic bars of the Effective RVE-filled model should have an effective width of $18 \mathrm{~cm}$ and an out-of-plane depth of $2 \mathrm{~cm}$, in order to obtain a good convergence of the dynamic response. The stress-strain curves for the two previously described equivalent models, subjected to harmonic loading with excitation frequency equal to $1 \mathrm{~Hz}, 2 \mathrm{~Hz}$ and $3 \mathrm{~Hz}$, respectively, are given in Figure 4 , where the dashed curves represent the dynamic response of the RVE-filled model and the continuous curves represent the dynamic response of the Effective RVE- filled model.

The calibrated viscoelastic bars can be also used in the following two scaled model cases, after proper modification:

Case A: Keeping the overall dimensions of the RVE the same, the size and the thickness of the honeycomb cells are scaled by a factor " $p$ ". If the length and width of the viscoelastic bars are also scaled by the same factor " $p$ ", then the stress-strain curves are similar to the ones of the original RVE configuration presented in the previous. Any out-of-plane dimensions are 
maintained the same.
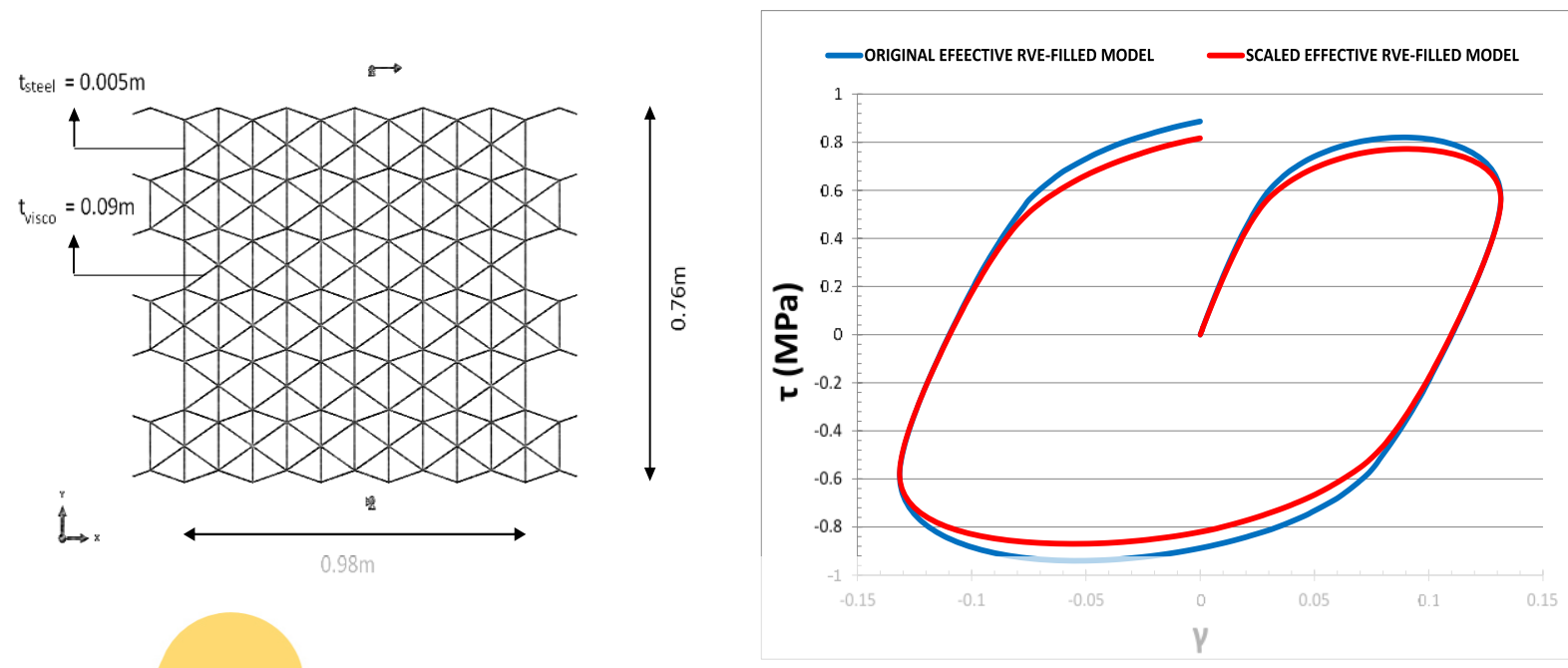

(a)

(b)

Figure 5: Case A - factor "p" = 1/2 : (a) Scaled Effective RVE-filled model ( $\mathrm{t}_{\text {steel }}=0.005 \mathrm{~m}$, $\left.\mathrm{t}_{\mathrm{visco}}=0.09 \mathrm{~m}\right)$. (b) Comparative stress-strain diagram for the scaled and the original Effective RVE-filled model.

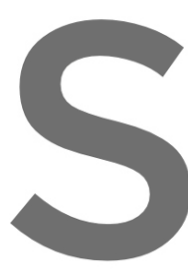

An example of a

equal to $1 / 2$ is given in Effective RVE-filled
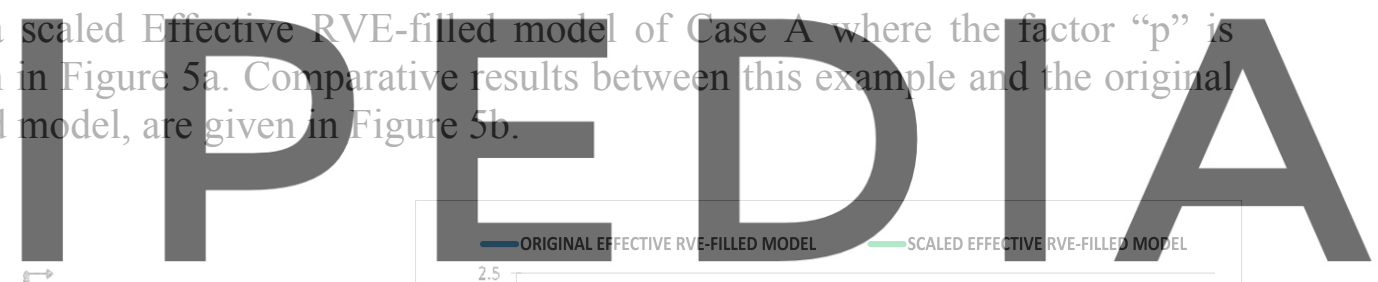

$\mathrm{t}_{\text {teel }}=0.01 \mathrm{~m}$

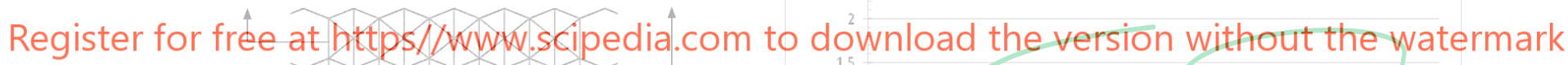

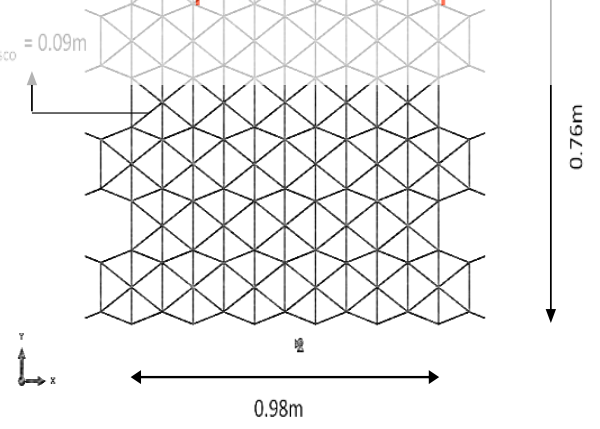

(a)

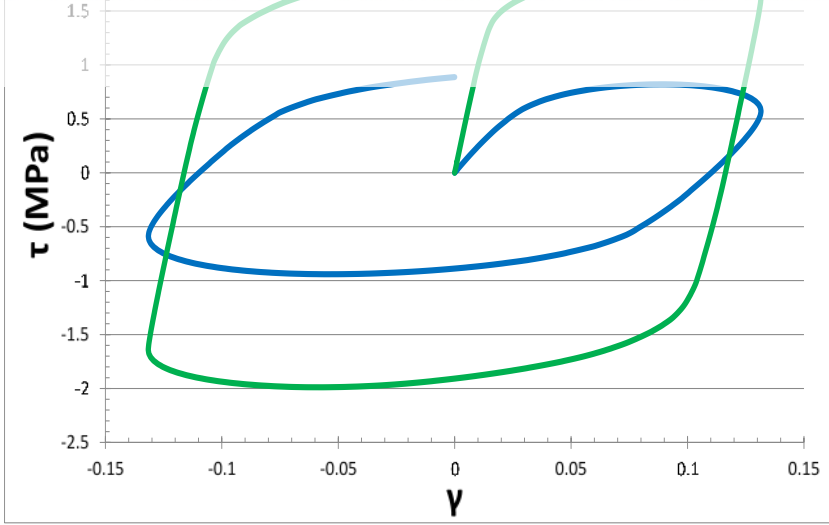

(b)

Figure 6: Case B - factor " $p$ " $=1 / 2$ : (a) Scaled Effective RVE-filled model ( $\left.t_{\text {steel }}=0.01 \mathrm{~m}, \mathrm{t}_{\text {visco }}=0.09 \mathrm{~m}\right)$. (b) Comparative stress-strain diagram for the scaled and the original Effective RVE-filled model.

Case B: Keeping the overall dimensions of the RVE the same, the size of the honeycomb cells are scaled by a factor "p", but this time the thickness of the honeycomb edges is not 
scaled. If the length and width of the viscoelastic bars are also scaled by the same factor "p", then the stress-strain curves are similar to the ones of the original RVE presented in the previous multiplied by a factor $1 / \mathrm{p}$. Any out-of-plane dimensions are maintained the same.

An example of a scaled Effective RVE-filled model of Case B where the factor "p" is equal to $1 / 2$ is given in Figure 6a. Comparative results between this example and the original Effective RVE-filled model, are given in Figure $6 \mathrm{~b}$.

At this point it should be mentioned that scaling by a factor " $p$ " the size of the honeycombs cells of the considered RVE while keeping the overall area of the RVE the same, results in a scaled model where the number of honeycomb cells is not $1 /(2 * p)$ larger than the initial seven honeycombs of the original RVE model, as expected. This is due to the geometric configuration of the selected RVE model and for the presented cases (Case A and Case B), it does not affect the overall performance of the scaled model with respect to the non-scaled one. For any other case different from Cases A and B, further investigation is needed.

\section{STRUCTURAL COMPONENT ANALYSIS}

The Effective RVE-filled model is now used in the structural component analysis of a fullscale shear wall system with geometric dimensions as given in Table 3.

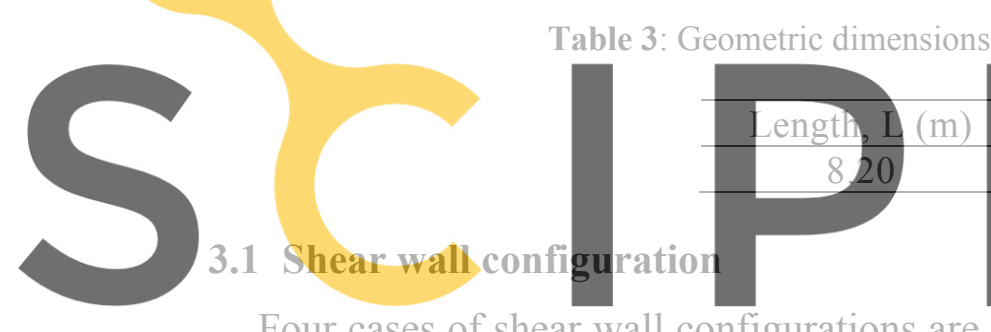

able 3: Geometric dimensions of the considered shear wall system

Four cases of shear wall configurations are considered as shown in Figure 7. The first case

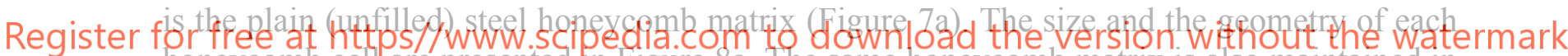
honeycomb cell are presented in Figure $8 \mathrm{a}$. The same honeycomb matrix is also maintained in the following three cases where the viscoelastic fillers are introduced. The configuration, shown in Figure $7 b$, is the fully filled shear wall, where all the honeycomb cells are filled with viscoelastic material. The filling rate of this configuration is equal to $100 \%$. The third configuration, is the 1-by-1 or "1-1" pattern (Figure 7c). In this case, the shear wall panel is separated in diagonal strips, with filled and unfilled strips alternately succeeding one another. Thus, the filling rate of the " $1-1$ " is equal to $50 \%$. Finally, the " $X$ " pattern is presented in Figure $7 \mathrm{~d}$. In this configuration, the filled cells are gathered around the two diagonals of the orthogonal shear wall. The average effective width of each diagonal is approximately three filled cells. The filling rate of the " $X$ " pattern is equal to $27 \%$.

Each one of the four aforementioned configurations is subjected to the harmonic excitation of Figure $8 \mathrm{~b}$. The excitation frequency is equal to $2 \mathrm{~Hz}$, whereas the amplitude is of $0.10 \mathrm{~m}$ (average shear strain or structural drift $0.1 / \mathrm{H}=0.023$ ).

At this point, it should be reminded that the Effective RVE-filled model as presented in Sections 2.2 and 2.3 of the present study, is employed in the dynamic analysis of the structural shear wall component. All computational analysis mentioned in the previous is carried out using ABAQUS software [28]. 


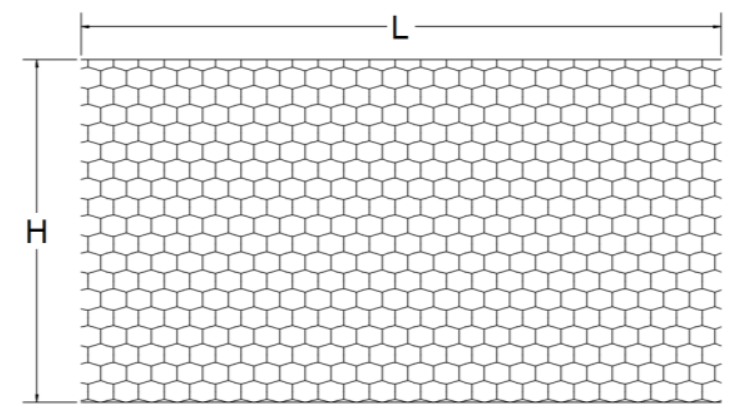

(a)

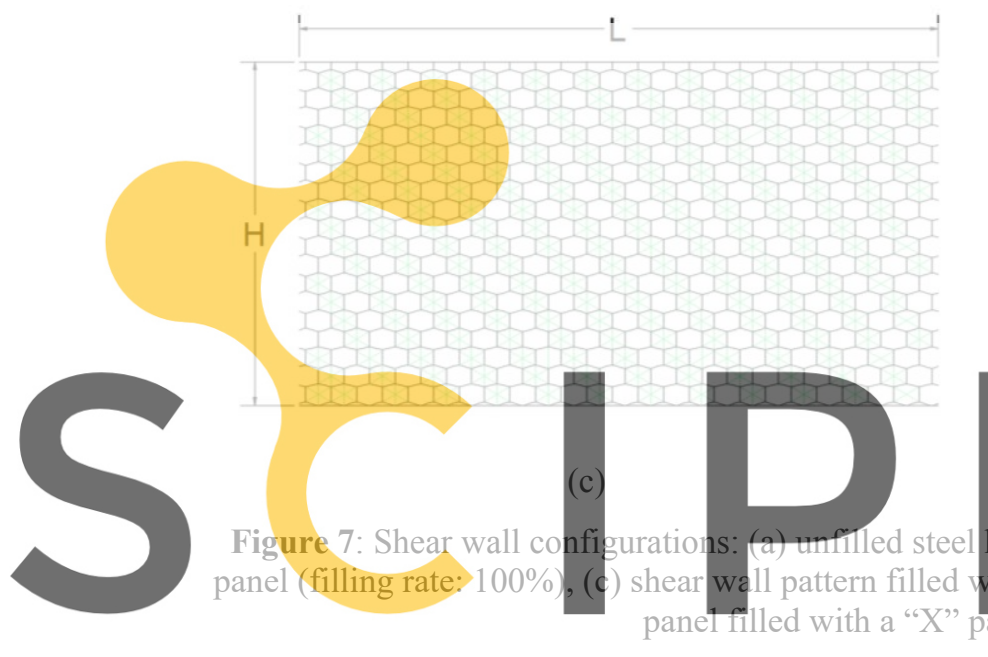

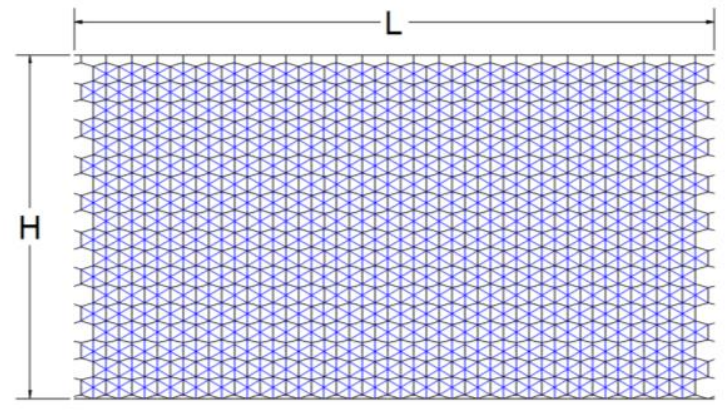

(b)

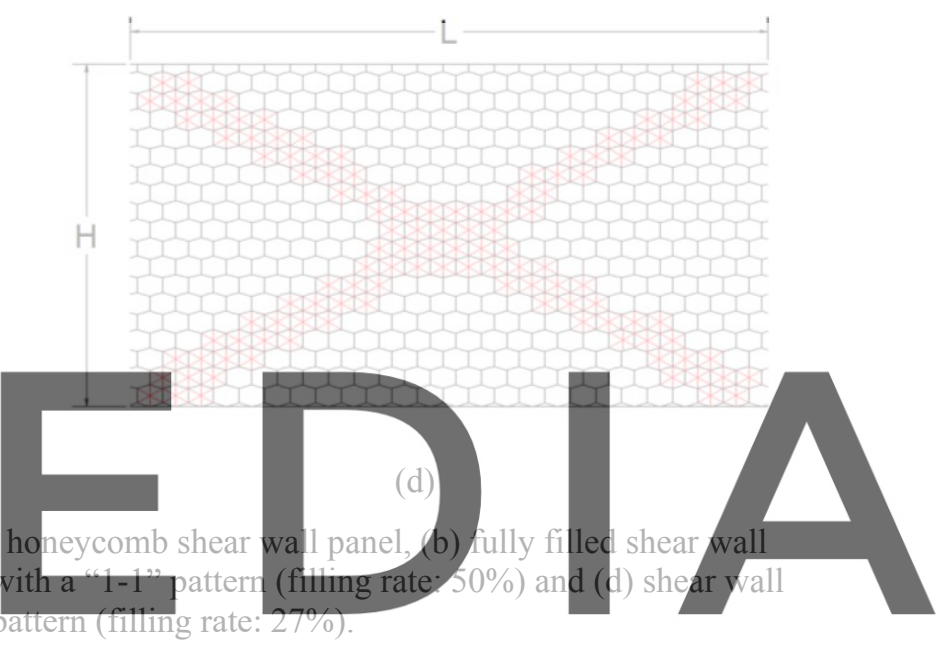

Register for free at https//www.scipedia.com to download the version without the watermark

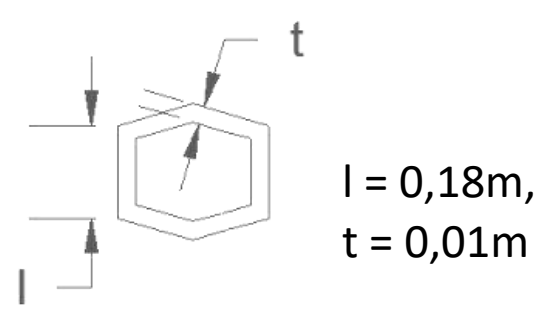

(a)

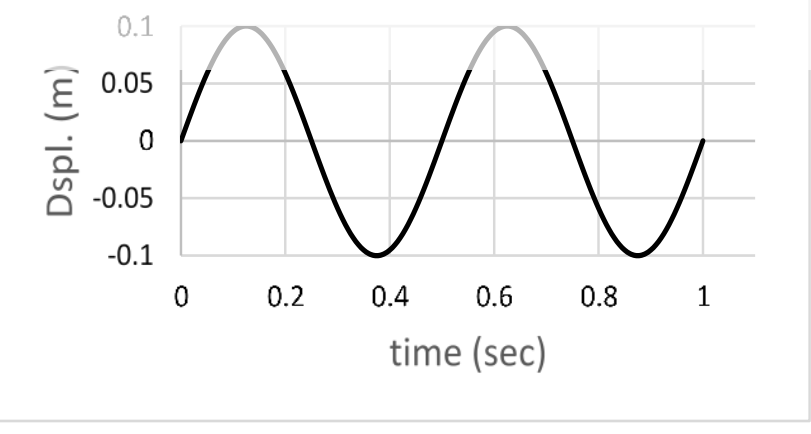

(b)

Figure 8: (a) Size and geometry of the honeycomb cells. (b) Harmonic excitation.

\subsection{Results}

Two groups of analysis are carried out. In the first group, structural steel of the honeycomb 
matrix is considered to behave linearly. The stress-strain curves of the four shear wall configurations, as described in the previous, are presented in Figure 9a. The fully filled configuration (filling ratio 100\%) has an overall improved dynamic behavior, in both terms of stiffness and damping, as expected. Focusing on the curves resulting from the "1-1" and the "X" pattern analysis, it is observed that the two cases exhibit a similar hysteretic behavior. However, considering the fact that the filling rate of the "1-1" pattern is approximately two times larger than the one of the " $X$ " pattern, the latter is more effective than the "1-1" pattern, since the same dynamic results are obtained with less viscoelastic material.

The second group includes the results of the harmonic analysis, obtained from the unfilled and the fully filled configurations, when the structural steel of the honeycomb matrix has a bilinear behavior. The stress-strain curves of this group are shown in Figure $9 b$.

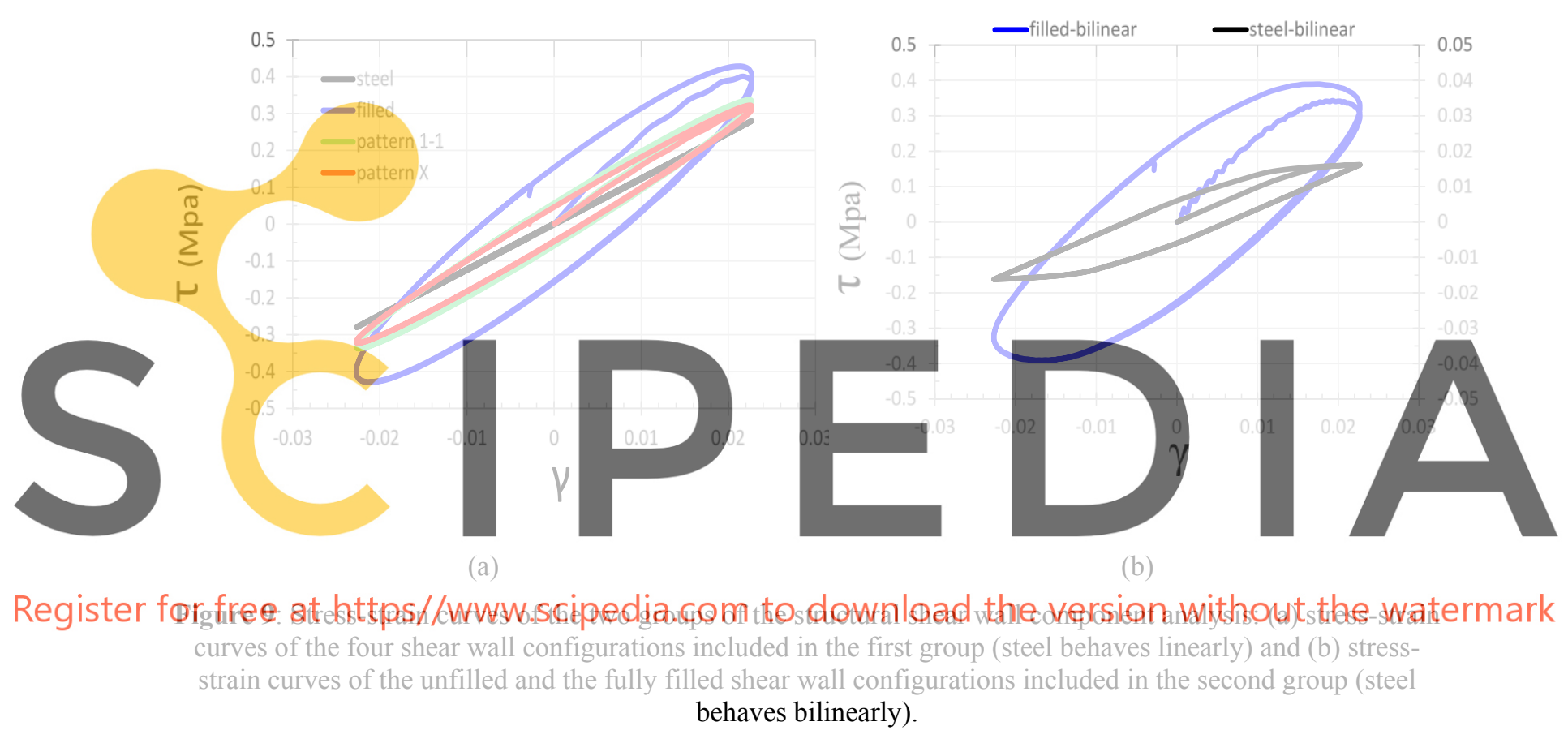

\section{ACKNOWLEDGEMENTS}

This research is carried out / funded in the context of the project "Investigation of the Mechanical Behavior of Structural Systems consisting of Innovative Cellular Architecture Meta-materials" (MIS 5049179) under the call for proposals "Researchers' support with an emphasis on young researchers- $2^{\text {nd }}$ Cycle". The project is co-financed by Greece and the European Union (European Social Fund- ESF) by the Operational Programme Human Resources Development, Education and Lifelong Learning 2014-2020.

\section{CONCLUSIONS}

In this paper a novel cellular shear wall system with viscoelastic fillers is proposed. After 
examining the contribution of the viscoelastic inclusions and the overall behavior of the combined cellular steel matrix - viscoelastic infills at a material level analysis, the use of a simplified computational model - under the label Effective RVE-filled model - where the fillers are simulated through viscoelastic beams of effective width attached to the hexagonal cell apexes, is suggested. Finally, a structural component analysis, where a full-sized shear wall system is tested under harmonic excitation, is carried out proving the validity and efficiency of the proposed cellular shear wall system with viscoelastic fillers, as the latter exhibits an improved dynamic response, in both terms of stiffness and damping. The results obtained from this study lead to the following conclusions:

- $\quad$ The proposed cellular shear wall with viscoelastic fillers can be a viable response modification system for seismic applications providing both stiffness and energy dissipation.

- $\quad$ Such a system can provide design flexibility, since hysteretic stiffness and damping of the steel honeycomb matrix are independent from the stiffness and damping of the viscoelastic filler. Thus, the designer can define the proportion between these features based on the requirements of the application, through the proper choice of geometric and material properties.

The proposed system is scalable. Both the cell and the overall shear wall dimensions can be scaled to fulfill the needs of each application.

The considered shear wall system prevents out-of-plane buckling under dynamic

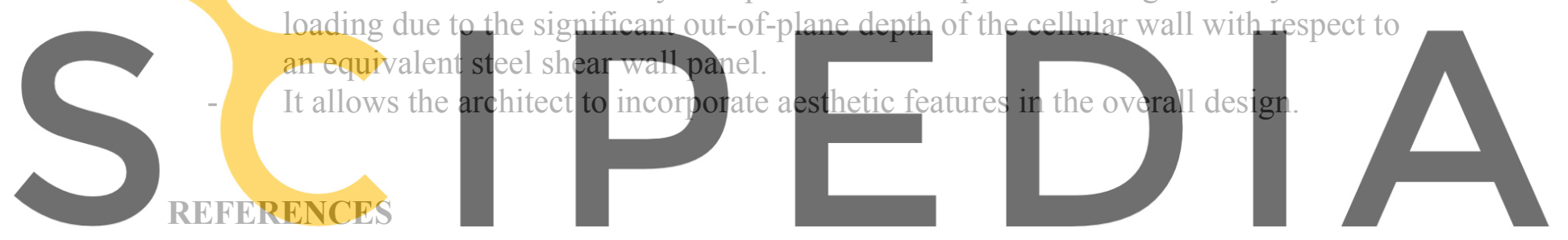

[1] Wood, R.H. Plasticity, composite action and collapse design of unreinforced shear wall

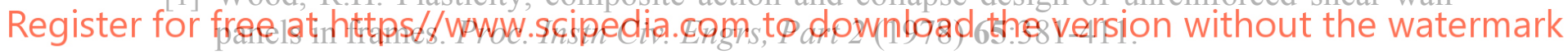

[2] Caccese, V., Elgaaly, M. and Chen, R. Experimental study of thin steel-plate shear walls under cyclic load. J. Siruct. Eng. (1993) 119:573-587.

[3] Elgaaly, M. Thin steel plate shear walls behavior and analysis. Thin-Walled Structures (1998) 32:151-180.

[4] Driver, R.G., Kulak, G.L., Kennedy, D.J.L. and Elwi, A.E. Cyclic test of four-story steel plate shear wall. J. Struct. Eng. (1998) 124:112-120.

[5] Lubell, A.S., Prion, H.G.L., Ventura, C.E. and Rezai, M. Unstiffened steel plate shear wall performance under cyclic loading. J. Struct. Eng. (2000) 126:453-460.

[6] Berman, J. and Bruneau, M. Plastic analysis and design of steel plate shear walls. $J$. Struct. Eng. (2003) 129:1448-1456.

[7] Vian, D. and Bruneau, M. Steel plate shear walls for seismic design and retrofit of building structures. Multidisciplinary Center for Earthquake Engineering Research, University at Buffalo, State University of New York, Technical Report MCEER-05-0010 (2005).

[8] Keller, D. and Bruneau, M. Development of a steel plate shear wall bridge pier system conceived from a multi-hazard perspective. Multidisciplinary Center for Earthquake 
Engineering Research, University at Buffalo, State University of New York, Technical Report MCEER-08-0030 (2008).

[9] Roberts, T.M. and Sabouri-Ghomi, S. Hysteretic characteristics of unstiffened perforated steel plate shear panels. Thin-Walled Structures (1992) 14:139-151.

[10] Purba, R. and Bruneau, M. Finite-element investigation and design recommendations for perforated steel plate shear walls. J. Struct. Eng. (2009) 135:1367-1376.

[11] Vian, D., Bruneau, M. and Purba, R. Special perforated steel plate shear walls with reduced beam section anchor beams. II: Analysis and design recommendations. J. Struct. Eng. (2009) 135:221-228.

[12] Foti, D., Diaferio, M. and Nobile, R. Optimal design of a new seismic passive protection device made in aluminium and steel. J. Str. Eng. Mech. (2010) 35(1):119-122.

[13] Chen, L. and Tsopelas, P. Cellular-solid shear walls under seismic excitations. Proceedings of 9th US National Conference on Earthquake Engineering, Toronto, July 2529 (2010).

[14] Papathanasiou, S.M., Tsopelas, P. and Zisis, T. Seismic performance of bridge systems enhanced with cellular-solid shear walls. IBRIDGE 2018, November 5-6, 2018, Istanbul, Turkey (2018).

[15] Murray, G., Gandhi, F. and Hayden, E. Polymer-filled honeycombs to achieve a structural material with appreciable damping. J. Int. Mat. Syst. Struct. (2012) 23:703-718.

[16] Boucher, M.-A., Smith, C.W., Scarpa, F., Rajasekaran, R. and Evans, K.E. Effective topologies for vibration inserts in honeycomb structures. Comp. Struct. (2013) 106:1-14.

[17] Aumjaud, P. Smith, C.W. and Evans, K.E. A novel viscoelastic damping treatment for honeycomb sandwich structures. Comp. Struct. (2015) 119:322-332.

[18] Ongaro, F., De Falco, P., Barbieri, E. and Pugno, N.M. Mechanics of filled cellular materials. Mechs of Mats. (2016) 97:26-47.

[19] Picu, C.R., Sorohan, S., Soare, M.A. and Constantinescu, D.M. Designing particulate composites: The effect of variability of filler properties and filler spatial distribution. Materials with Internal Structure, Springer Tracts in Mechanical Engineering, DOI 10.1007/978-3-319-21494-8_7, (2016).

[20] Wang, Y.C., Lai, H.-W. and Ren, W.J. Enhanced auxetic viscoelastic properties of filled reentrant honeycomb. Phys. Status Solidi B (2019), DOI: 10.1002/pssb.201900184.

[21] Zhang, R.-H. and Soong, T.T. Seismic design of viscoelastic dampers for structural applications. J. Struct. Eng. (1992) 118:1375-1392.

[22] Kasai, K. and Munshi, J.A. Applications of viscoelastic dampers to high-rise buildings. J. Struct. Eng. (1994) 120:3680-3683.

[23] Samali, B. and Kwok, K.C.S. Use of viscoelastic dampers in reducing win- and earthquake- induced motion of building structures. Eng. Struct. (1995) 17:639-654.

[24] Shimizu, N., Nasuno, H., Yazaki, T. and Sunakoda, K. Design and analysis of viscoelastic seismic dampers. PVP2002, August 5-9, 2002, Vancouver, BC, Canada (2002).

[25] Jung, W.-Y. and Aref, A.J. A combined honeycomb and solid viscoelastic material for structural damping applications. Mechs of Mats. (2003) 35:831-844.

[26] Symans, M.D., Charney, F.A., Whittaker, A.S., Constantinou, M.C., Kircher, C.A., Johnson, M.W. and McNamara, R.J. Energy dissipation systems for seismic applications: Current practice and recent developments. J. Struct. Eng. (2008) 134(1): 3-21. 
[27] Shen, K.L. and Soong, T.T. Modeling of viscoelastic dampers for structural applications. J. Eng. Mech. (1995) 121:694-701.

[28] ABAQUS/Standard User's Manual, Version 6.14. 